\title{
Re: Pregnancies in women with Turner Syndrome: A retrospective multicentre UK study
}

\author{
Niels Andersen ${ }^{1}$ and Claus Gravholt ${ }^{2}$ \\ ${ }^{1}$ Odense Universitetshospital \\ ${ }^{2}$ Aarhus University Hospital
}

December 17, 2021

Re: Pregnancies in women with Turner Syndrome: A retrospective multicentre UK study

Niels Holmark Andersen ${ }^{1}$, Claus Højbjerg Gravholt ${ }^{2-3}$

1. Department of Cardiology, Aalborg University Hospital, Hobrovej 18-22, DK-9000 Aalborg

2. Department of Endocrinology and Internal Medicine, Aarhus University Hospital, Aarhus, Denmark DK8200 Aarhus N

3. Department of Molecular Medicine, Aarhus University Hospital, DK-8200 Aarhus N, Denmark

Corresponding author:

Niels Holmark Andersen

Department of Cardiology, Aalborg University Hospital, Hobrovej 18-22, DK-9000 Aalborg

holmark@ki.au.dk

ORCID:

NHA: 0000-0002-5394-3016

CHG: 0000-0001-5924-1720

Sir,

We read with interest the article by Cauldwell et al., which concluded that pregnancy in women with Turner syndrome is associated with major maternal cardiovascular risks and cardiovascular assessment and counselling prior to assisted or spontaneous pregnancy should be managed by a specialist team.

These conclusions are based on data from 127 pregnancies in 81 women with Turner syndrome.

Cauldwell et al. describe data from 16 different centres with one to 42 pregnancies per centre over an observation period of 20 years. Details on pregnancies per centre are not presented but there must have been many centres where a Turners syndrome pregnancy was a rarity not even happening once a year. When analysing the numbers, it seems that the different centres beyond the centre with 42 cases will have seen an average of 6 pregnant women with Turner syndrome over 20 years. This must have had significant impact on the experience and expertise of the obstetricians in the different centres. Could this be the reason why the caesarean section rates where markedly higher than other wise reported?

In the present article the rate was 61-67\% compared to data from Sweden where it was $38 \%$ and $47 \%$ in France. ${ }^{1-2}$ 
It is also stated that pregnancies in Turner syndrome are associated with major cardiovascular risks based upon three events. One woman suffered a type A dissection at 18 weeks gestation despite a normal aortic size but a bicuspid aortic valve. No other details about hypertension, aortic morphology or growth rates are presented. The two other events were women with severe aortic disease. It is unclear whether these women were counselled and offered prophylactic aortic surgery before pregnancy. So, in two out of three cases it is possible that the adverse outcomes were due to inadequate clinical care.

In this cohort only $57.4 \%$ had seen a cardiologist within 24 months before getting pregnant, which is far from what is necessary in the caretaking of women with Turner syndrome and a childbearing potential.

Data from Scandinavia, France, and from the Alliance for Adult Research in Congenital Cardiology tells another story. ${ }^{2-4}$ In these cohorts the number of pregnancy related dissections was very low due to prepregnancy counselling, centralised follow-up, and timely prophylactic aortic surgery before considerations about normal pregnancy or egg donation. This simply generates better results.

A safe pregnancy and childbirth are very important for women with Turner syndrome. What we can learn from this article is what not to do. Pregnancy and delivery in women with Turner syndrome must be centralised and a timely cardiovascular assessment of women with Turner syndrome and a pregnancy wish should be mandatory. Otherwise, we will end with results as described in this article.

In other words, the conclusion of the article should have been lack of centralisation and appropriate cardiovascular pre-pregnancy assessment leads to increased morbidity and cardiovascular risk. If such pre-pregnancy assessment is in place and caretaking is centralised, cardiovascular risk during pregnancy is very low in Turner syndrome. ${ }^{1-4}$

1. Hagman A, Källén K, Barrenäs M-L, Landin-Wilhelmsen K, Hanson C, Bryman I, et al. Obstetric outcomes in women with Turner karyotype. J Clin Endocrinol Metab. 2011; 96: 3475-82.

2. Bernard V, Donadille B, Zenaty D, Courtillot C, Salenave S, Brac de la Perrière A, et al. Spontaneous fertility, and pregnancy outcomes amongst 480 women with Turner syndrome. Hum Reprod 2016; 31:782-8.

3. Hagman A, Loft A, Wennerholm U-B, Pinborg A, Bergh C, Aittomäki K, et al. Obstetric and neonatal outcome after oocyte donation in 106 women with Turner syndrome: a Nordic cohort study. Hum Reprod 2013; 28: 1598-609.

4. Grewal J, Valente AM, Egbe AC, Wu FM, Krieger EV, Sybert VP et al. Cardiovascular outcomes of pregnancy in Turner syndrome. Heart 2021;107:61-6.

Conflicts of interest: None to declare 